BIOMEDICAL AND BIOSOCIAL ANTHROPOLOGY
$\begin{gathered}\text { Official Journal of the International Academy } \\ \text { of Integrative Anthropology } \\ \text { journal homepage: http://bba-journal.com }\end{gathered}$

\title{
Transverse body sizes in men and women with seborrheic dermatitis of varying severity
}

\section{Khasawneh Ahmad Raed}

National Pirogov Memorial Medical University, Vinnytsya, Ukraine

\section{ARTICLE INFO}

Received: 19 March 2021

Accepted: 23 April 2021

UDC: $616.53-008.811 .1-037-084-$

036.1:616-071.2

\section{CORRESPONDING AUTHOR}

e-mail: dr_ahmad_khasawneh@yahoo.com Khasawneh Ahmad Raed

\begin{abstract}
Transverse dimensions of the body as morphogenetic markers within the constitutional integrity of the organism involve the identification of their connection with the adaptive abilities of man and they are studied in the process of ontogenesis under the influence of the environment. Establishing the patterns of intersystem connections will further develop a system of criteria for prognostic assessment of the risk of seborrheic dermatitis based on the phenotypology of human body parameters. The aim of the study was to establish and analyze the features of the width of the distal epiphyses of the long tubular bones of the extremities and the transverse diameters of the body in men and women with seborrheic dermatitis of varying severity. The width of the distal epiphyses of the long tubular bones of the extremities and transverse diameters of the body in 40 men and 40 women (aged 25 to 44 years) with generalized fatty seborrheic dermatitis (mild and severe) were determined. The control group consisted of indicators of the width of the distal epiphyses of long tubular bones of the extremities and transverse body diameters of practically healthy men $(n=82)$ and women $(n=154)$ of the same age group, selected from the National Pirogov Memorial Medical University, Vinnytsya. Statistical processing of body circumference was performed in the licensed package "Statistica 6.0" using non-parametric estimation methods. As a result of studies in patients with seborrheic dermatitis of varying severity of men, compared with practically healthy men, found only greater values of transverse middle thoracic diameter, anteroposterior middle sternal diameter, intertrochanteric distance, as well as smaller values of shoulder width and distal shoulder width; and in patients of varying severity of women - in almost all cases (except for the width of the distal epiphysis of the shoulder) found greater values of the width of the distal epiphyses of the long tubular bones of the limbs and transverse body diameters (except shoulder width). Moreover, both in sick men and women, differences in transverse body size are more pronounced in people with severe seborrheic dermatitis. Among men or women with seborrheic dermatitis of varying severity, there is only a tendency for greater values in women with severe transverse lower thoracic diameter and intertrochanteric distance, and in men with severe - a tendency to greater values of the distal forearm width. There are also pronounced manifestations of sexual dimorphism of the width of the distal epiphyses of the long tubular bones of the limbs and transverse diameters of the body (except for pelvis sizes), namely - higher values of these indicators in patients with seborrheic dermatitis of varying severity.
\end{abstract}

Keywords: seborrheic dermatitis, Ukrainian men and women, transverse body sizes, sex differences.

\section{Introduction}

According to modern epidemiological studies, seborrheic dermatitis is a fairly common chronic dermatosis. Moreover, in the world population, regardless of ethnic, climatic, geographical, socio-economic, sexual factors, there is not only an increase in the incidence of seborrheic dermatitis, but also an increase in the severity of severe, resistant to treatment [3]. Seborrheic dermatitis rarely leads to disability or death of the patient, but significantly impairs the quality of life of the patient, his social and occupational adaptation. Significant financial 
costs for therapy are due to long-term current and preventive treatment [11].

The basis of clinical manifestations of seborrheic dermatitis is hyperkeratosis, necrosis of keratinocytes of varying severity. Superficial hyperemia of arterial vessels, insignificant perivascular infiltrate consisting of plasma cells and neutrophils, with the phenomena of leukocytoclasia are observed in the dermis. Increased reproduction of epidermal cells with a violation of the process of differentiation leads to the formation of a defective stratum corneum on the background of inflammatory phenomena in the dermis [12].

Despite the fact that the etiopathogenesis of seborrheic dermatitis is comprehensively and intensively studied, the mechanisms of development of this dermatosis remain much unclear. Numerous publications consider seborrheic dermatitis as a multifactorial disease with polygenic predisposition to the hereditary component of the predisposition. Under the multifactorial development of this dermatosis is the implementation of a genetic program under the influence of numerous exogenous and endogenous causes [1, 13].

There are a number of neurogenic, psychological, hormonal, immune, infectious, metabolic, genetic factors that contribute to the manifestation of this dermatosis, which cause excessive production and quality change of sebum caused by functional activity of sebaceous glands and increased number and activation of fungi of the genus Malassezia. Psychogenic factors act as a link in the chain of successive immunological processes, which explains the occurrence or exacerbation of dermatosis only in close connection with the main factors of pathogenesis $[7,15$, 20]. The adult form of seborrheic dermatitis is often associated with neurological diseases, in addition, the tendency to recur may be a skin marker of acquired immunodeficiency syndrome. Seasonal fluctuations in temperature and humidity affect the course of the disease, so that in the cold season, exacerbations of seborrheic dermatitis are more common [2].

The study of the relationship between the constitutional features of man and the course of disease today is an important stage in the development of modern medicine. The type of physique is genetically determined and is a constant objective characteristic of a person during ontogenesis. Age-related changes, diseases, excessive or insufficient physical activity change the contours and size of the body, but not the somatotype [17]. To date, significant clinical and theoretical material has been accumulated, which substantiates the significant role of somatotype in the occurrence and development of dermatoses in humans [6, $8,9,10]$. At the same time, when analyzing the literature, we did not find any work devoted to the study of the influence of body type on the course of seborrheic dermatitis.

The aim of the study was to establish and analyze the features of the width of the distal epiphyses of the long tubular bones of the extremities and the transverse diameters of the body in men and women with seborrheic dermatitis of varying severity.

\section{Materials and methods}

On the basis of the Department of Dermatology and Venereal Diseases with a postgraduate course in National Pirogov Memorial Medical University, Vinnytsia and the Military Medical Clinical Center of the Central Region conducted a survey of 40 men and 40 young women (2544 years according to WHO age period, 2015) patients with generalized fatty seborrheic dermatitis (mild and severe course).

The Bioethics Committee of the National Pirogov Memorial Medical University, Vinnytsya (Minutes № 10 of 26.11.2020) found that the studies did not contradict the basic bioethical standards of the Helsinki Declaration, the Council of Europe Convention on Human Rights and Biomedicine (1977), WHO regulations and Ukrainian law.

The diagnosis of seborrheic dermatitis was established on the basis of the subject's complaints, life history and illness, examination of the face, scalp, torso and extremities with assessment of subjective and objective signs of the disease.

Anthropometric survey was conducted in accordance with the scheme of Bunak V. V. [4]. Measurement of the width of the distal epiphyses of the long tubular bones of the extremities $(\mathrm{cm})$ was performed with a caliper, the accuracy of which was up to $0.01 \mathrm{~cm}$ Measured: distal shoulder epiphysis (EPPL), distal forearm epiphysis (EPPR), distal femoral epiphysis (EPB) and the width of the distal epiphysis of the shoulder shins (EPG). Measurements of transverse body diameters $(\mathrm{cm})$ and pelvic dimensions $(\mathrm{cm})$ were performed using a large thickness compass. Measured: transverse middle-thoracic diameter (PSG), transverse lower-thoracic diameter (PNG), anterior-posterior middle-sternal diameter (SGK), shoulder width (ACR), intercristal distance (CRIS), snterspinous distance (SPIN), intertrochanteric distance (TROCH) and only in women surface conjugate (CONJ).

The control group consisted of distal epiphyseal widths of long tubular limb bones and transverse body diameters of practically healthy men $(n=82)$ and women $(n=154)$ of the same age group, selected from the National Pirogov Memorial Medical University database, Vinnytsya.

Statistical processing of the results was performed in the license package "Statistica 6.0" using non-parametric evaluation methods. The reliability of the difference between the values between the independent quantitative values was determined using the U-Mann-Whitney test.

\section{Results}

Table 1 presents the results of comparing the width of the distal epiphyses of the long tubular bones of the extremities and the transverse diameters of the body between healthy and patients with mild and severe seborrheic dermatitis men and/or women. 


\section{Discussion}

It is suggested that one of the main factors in the development of seborrheic dermatitis is a hereditary predisposition. This is characterized by the so-called "seborrheic constitution", which reflects a high genetic predisposition to the development of this disease. Usually such patients have a family history [2, 3].

Polesko I. V. make [14] analysis of class I HLA antigens and specificity of DRB1, DQA1, DQB1 class II in patients with this skin disease substantiated the existence of genetic determinism of this disease and included among the probable markers class I antigens $A 10$ and A23. This changes the microbiota of the skin and reduces its bactericidal properties, creating a favorable environment for pathogenic flora that provokes inflammation [18].

Clinically significant differences in skin between ethnic groups have been reported, especially not only skin color (more often people with white skin are prone to the disease), but the processes of formation and secretion of sebum [19, 21]. The genetic nature of the disease is justified by the possibility of irregular dominance of seborrheic dermatitis and the most common manifestation in patients with III (B) blood group [16].

It should be noted that in previous years the

Table 1. Comparison of the width of the distal epiphyses of the long tubular bones of the extremities and the transverse diameters of the body between healthy and patients with seborrheic dermatitis of varying severity in men and/or women ( $\mathrm{M} \pm \sigma)$.

\begin{tabular}{|c|c|c|c|c|c|c|}
\hline \multirow{2}{*}{ Indicators } & \multirow{2}{*}{ Healthy men ( $n=82$ ) } & \multicolumn{2}{|c|}{ Men with seborrheic dermatitis } & \multirow{2}{*}{$P_{n-m c}$} & \multirow{2}{*}{$P_{h-s c}$} & \multirow{2}{*}{$P_{m c-s c}$} \\
\hline & & $M C(n=20)$ & $S C(n=20)$ & & & \\
\hline EPPL & $6.899 \pm 0.438^{* * *}$ & $6.710 \pm 0.408^{* * *}$ & $6.815 \pm 0.470^{* \star *}$ & $<0.05$ & $>0.05$ & $>0.05$ \\
\hline EPPR & $5.724 \pm 0.327^{\star * *}$ & $5.650 \pm 0.328^{* * *}$ & $5.805 \pm 0.365^{\text {***}}$ & $>0.05$ & $>0.05$ & $=0.060$ \\
\hline EPB & $8.917 \pm 0.437^{* * *}$ & $9.030 \pm 0.779 t$ & $9.085 \pm 0.935$ & $>0.05$ & $>0.05$ & $>0.05$ \\
\hline EPG & $7.277 \pm 0.469^{\star * *}$ & $7.435 \pm 0.354^{\star \star}$ & $7.340 \pm 0.485^{\star \star *}$ & $>0.05$ & $>0.05$ & $>0.05$ \\
\hline PSG & $28.35 \pm 2.19^{* \star *}$ & $30.20 \pm 2.53^{* \star *}$ & $30.40 \pm 2.84^{* *}$ & $<0.01$ & $<0.01$ & $>0.05$ \\
\hline$P N G$ & $25.30 \pm 2.26^{\star \star \star}$ & $25.80 \pm 2.17^{\star \star \star}$ & $26.05 \pm 2.61^{* *}$ & $>0.05$ & $>0.05$ & $>0.05$ \\
\hline SGK & $19.93 \pm 2.12^{* * *}$ & $22.60 \pm 2.52^{\star * *}$ & $25.65 \pm 16.09^{* *}$ & $<0.001$ & $<0.001$ & $>0.05$ \\
\hline ACR & $42.02 \pm 2.64^{* \star *}$ & $36.30 \pm 2.87^{\star \star \star}$ & $35.70 \pm 3.13^{*}$ & $<0.001$ & $<0.001$ & $>0.05$ \\
\hline SPIN & $26.33 \pm 1.98^{* \star *}$ & $26.45 \pm 2.54$ & $26.25 \pm 2.05$ & $>0.05$ & $>0.05$ & $>0.05$ \\
\hline CRIS & $29.38 \pm 2.02^{* * *}$ & $29.90 \pm 2.61$ & $29.45 \pm 2.31$ & $>0.05$ & $>0.05$ & $>0.05$ \\
\hline $\mathrm{TROCH}$ & $32.96 \pm 2.10^{*}$ & $33.85 \pm 2.35 t$ & $34.15 \pm 2.06$ & $=0.083$ & $<0.05$ & $>0.05$ \\
\hline \multirow{2}{*}{ Indicators } & \multirow{2}{*}{ Healthy women $(n=154)$} & \multicolumn{2}{|c|}{ Women with seborrheic dermatitis } & \multirow{2}{*}{$P_{n-m c}$} & \multirow{2}{*}{$P_{h-s c}$} & \multirow{2}{*}{$\mathrm{P}_{\mathrm{mc}-\mathrm{sc}}$} \\
\hline & & $M C(n=20)$ & $S C(n=20)$ & & & \\
\hline EPPL & $5.969 \pm 0.387$ & $5.990 \pm 0.602$ & $6.070 \pm 0.492$ & $>0.05$ & $>0.05$ & $>0.05$ \\
\hline EPPR & $4.937 \pm 0.286$ & $4.975 \pm 0.406$ & $5.045 \pm 0.272$ & $>0.05$ & $=0.067$ & $>0.05$ \\
\hline EPB & $8.172 \pm 0.529$ & $8.685 \pm 1.049$ & $8.815 \pm 0.778$ & $=0.094$ & $<0.001$ & $>0.05$ \\
\hline EPG & $6.483 \pm 0.408$ & $6.575 \pm 0.445$ & $6.755 \pm 0.391$ & $>0.05$ & $<0.01$ & $>0.05$ \\
\hline PSG & $25.09 \pm 1.94$ & $26.45 \pm 1.90$ & $27.65 \pm 2.78$ & $<0.01$ & $<0.001$ & $>0.05$ \\
\hline PNG & $21.62 \pm 1.91$ & $22.60 \pm 1.90$ & $23.90 \pm 2.51$ & $<0.05$ & $<0.001$ & $=0.079$ \\
\hline SGK & $17.18 \pm 1.53$ & $19.35 \pm 1.39$ & $20.00 \pm 2.20$ & $<0.001$ & $<0.001$ & $>0.05$ \\
\hline ACR & $36.81 \pm 2.35$ & $32.05 \pm 3.05$ & $32.90 \pm 3.46$ & $<0.001$ & $<0.001$ & $>0.05$ \\
\hline SPIN & $25.09 \pm 2.23$ & $25.80 \pm 2.12$ & $26.55 \pm 1.90$ & $>0.05$ & $<0.01$ & $>0.05$ \\
\hline CRIS & $27.52 \pm 2.78$ & $28.80 \pm 2.31$ & $29.40 \pm 2.19$ & $=0.080$ & $<0.01$ & $>0.05$ \\
\hline TROCH & $32.31 \pm 1.92$ & $32.60 \pm 2.74$ & $33.95 \pm 2.72$ & $>0.05$ & $<0.01$ & $=0.079$ \\
\hline CONJ & $18.83 \pm 1.71$ & $21.18 \pm 2.09$ & $21.50 \pm 2.09$ & $<0.001$ & $<0.001$ & $>0.05$ \\
\hline
\end{tabular}

Notes: MC - mild course; SC - severe course; $p_{n-m}$ - the significance of the difference between the values of indicators between healthy and patients with mild seborrheic dermatitis; $\mathrm{p}_{\mathrm{h}-\mathrm{sc}}$ - the significance of the difference between the values of indicators between healthy and patients with severe seborrheic dermatitis; $p_{\mathrm{mc}-\mathrm{sc}}$ - the significance of the difference between the values of indicators between patients with seborrheic dermatitis of mild and severe severity; ${ }^{*}$ - the reliability of the difference in the values of the relevant indicators between men and women at the level $p<0.05$; ${ }^{* *}$ - the reliability of the difference in the values of the relevant indicators between men and women at the level $p<0.01 ;{ }^{* * *}$ - the reliability of the difference in the values of the relevant indicators between men and women at the level $p<0.001 ; t$ - trends in the difference between the values of the respective indicators between men and women. 
establishment of the basic patterns of group and intergroup variability of seborrheic dermatitis at the phenotypic level when comparing them with genetic variability was carried out with blood groups or other serological traits. However, in this regard, the constitutional approach is still a little-studied area. The main task of modern integrative anthropology has long been the search for the notorious "mechanisms of inheritance of body type", although such appeals continue to be heard. One of the most promising areas of its development is the establishment of intersystemic patterns of morphological variability of man in line with the establishment of constitutional markers of certain diseases. The search for quantitative morphological regularities and their distribution according to individual dimensional (quantitative) regularities is, first of all, the search for regularities of phenotypic manifestation of cluster genes, which can provide no less new information than direct isolation of genes and study of molecular mechanisms of their expression [5].

When analyzing the width of the distal epiphyses of the long tubular bones of the extremities and the transverse diameters of the body between healthy and patients with seborrheic dermatitis of varying severity in Ukrainian men or women found the following significant or trends of differences (Table 2, see Table 1):

- between healthy and sick men - in practically healthy

Table 2. Differences in transverse body sizes between healthy and patients with seborrheic dermatitis of varying severity in men and/or women.

\begin{tabular}{|l|c|c|c|c|c|c|}
\hline \multirow{2}{*}{ Indicators } & \multicolumn{3}{|c|}{ Men } & \multicolumn{3}{c|}{ Women } \\
\hline & $\mathrm{H}$ & $\mathrm{MC}$ & $\mathrm{SC}$ & $\mathrm{H}$ & $\mathrm{MC}$ & $\mathrm{SC}$ \\
\hline EPPL & $\Delta$ & $\nabla$ & & & & \\
\hline EPPR & & $\downarrow$ & $\uparrow$ & $\downarrow$ & & $\uparrow$ \\
\hline EPB & & & & $\nabla \downarrow$ & $\uparrow$ & $\Delta$ \\
\hline EPG & & & & $\nabla$ & & \\
\hline PSG & $\nabla$ & $\Delta$ & $\Delta$ & $\nabla$ & & $\Delta$ \\
\hline PNG & & & & $\nabla$ & $\Delta$ & $\Delta$ \\
\hline SGK & $\nabla$ & $\Delta$ & $\Delta$ & $\nabla$ & $\Delta \downarrow$ & $\Delta \uparrow$ \\
\hline ACR & $\Delta$ & $\nabla$ & $\nabla$ & $\Delta$ & $\Delta$ & $\Delta$ \\
\hline SPIN & & & & $\nabla$ & $\nabla$ & $\nabla$ \\
\hline CRIS & & & & $\nabla \downarrow$ & $\uparrow$ & $\Delta$ \\
\hline TROCH & $\nabla \downarrow$ & $\uparrow$ & $\Delta$ & $\nabla$ & $\downarrow$ & $\Delta \uparrow$ \\
\hline CONJ & & & & $\nabla$ & $\Delta$ & $\Delta$ \\
\hline
\end{tabular}

Notes: $\mathrm{H}$ - healthy; MC - seborrheic dermatitis of mild course; SC - seborrheic dermatitis of severe course; $\Delta$ or $\nabla$ - significant differences between healthy and sick men; $\uparrow$ or $\downarrow$ - trends in differences between healthy and sick men; $\Delta$ or $\nabla$ - significant differences in performance between sick women; $\uparrow$ or $\downarrow$ tendencies of differences of indicators between sick women; significantly higher indicators are highlighted in green when comparing the respective groups between men and women; tendencies to higher values of indicators when comparing the respective groups between men and women are highlighted in yellow. men lower values of transverse middle-thoracic $(6.1 \%$ and $6.7 \%$, respectively), anterior-posterior middle-sternal $(11.8 \%$ and $22.3 \%$, respectively) diameters and intertrochanteric distance $(2.6 \%$ and $3.5 \%$ respectively), as well as higher values of shoulder width (by $13.6 \%$ and $15.0 \%$, respectively) and width of the distal epiphysis of the shoulder (only compared to mild severity by $2.7 \%$ );

- between healthy and sick women - in practically healthy women lower values of width of the distal epiphyses of the forearms (only compared to severe by $2.1 \%$ ), thighs (by $5.9 \%$ and $7.3 \%$, respectively) and shins (only compared to severe by $4.0 \%)$, transverse middle-thoracic $(5.1 \%$ and $9.3 \%$ respectively) and lower-thoracic (4.3\% and $9.5 \%$ respectively) diameters, anterior-posterior middle-sternal diameter (11.2\% and $14.1 \%$ respectively), interspinous (only compared with severe by $5.5 \%$ ), intercristal (4.4\% and $6.4 \%$, respectively), intertrochanteric distances (only $4.8 \%$ compared with severe) and surface conjugates (11.1\% and $12.4 \%$, respectively), and also higher values of shoulder width (by $12.9 \%$ and $10.6 \%$, respectively).

When comparing the width of the distal epiphyses of the long tubular bones of the extremities and the transverse diameters of the body between patients with seborrheic dermatitis of varying severity Ukrainian men or women, we found only tendencies to higher values in patients with severe women transverse lower-thoracic diameter by $5.4 \%$ intertrochanteric distance by $4.0 \%$ compared with women with mild disease course, and the tendency to higher values in patients with severe male severity of the width of the distal epiphysis of the forearm by $2.7 \%$ compared with men with mild disease course (see Table 1, 2).

In the analysis of sexual differences in the width of the distal epiphyses of the long tubular bones of the limbs and transverse diameters of the body between patients with seborrheic dermatitis of varying severity in Ukrainian men found significantly greater or greater tendency to greater width of the distal epiphyses (by $10.7 \%$ and $10.9 \%$, respectively), forearms (respectively by $11.9 \%$ and $13.1 \%$ ), thighs (only compared to mild severity by $3.8 \%$ ) and shins (by $11.6 \%$ and $8.0 \%$ respectively), transverse middle-thoracic (by $12.4 \%$ and $9.0 \%$ respectively) and lower-thoracic (12.4\% and $8.3 \%$, respectively) diameters, anterior-posterior middle-sternal diameter $(14.4 \%$ and $22.0 \%$, respectively), shoulder width $(11.7 \%$ and $7.8 \%$, respectively), and intertrochanteric distance (only compared to mild $3.7 \%$ ) (see Tables 1, 2). In contrast to practically healthy men and women, no significant or tendency differences between interspinous and intercristal distance were found between patients (see Tables 1, 2).

Transverse dimensions of the body as morphogenetic markers within the constitutional integrity of the organism involve the identification of their connection with the adaptive abilities of man and they are studied in the process of ontogenesis under the influence of the environment. Establishing the patterns of manifestation of intersystem connections will further develop a system of criteria for 
prognostic assessment of the risk of seborrheic dermatitis based on the phenotypology of body parameters.

\section{Conclusion}

1. In patients of varying severity women (more severe course) compared with practically healthy women, in almost all cases (except for the width of the distal epiphysis of the shoulder) found significant or trends in differences in the width of the distal epiphyses of long tubular limbs and transverse body diameters (larger values except for shoulder width). Patients with seborrheic dermatitis of varying severity men, compared with practically healthy men, found fewer differences in the width of the distal epiphyses of the long tubular bones of the extremities and transverse diameters of the body (only greater values of transverse

\section{References}

[1] Augustin, M., Kirsten, N., Körber, A., Wilsmann-Theis, D., Itschert G., Staubach-Renz, P., ... \& Zander, N. (2019). Prevalence, predictors and comorbidity of dry skin in the general population. Journal of the European Academy of Dermatology and Venereology, 33(1), 147-150. doi: 10.1111/jdv.15157

[2] Bas, Y., Seckin, H. Y., Kalkan, G., Takci, Z., Citil, R., Onder, Y., ... Demir, A. K. (2016). Prevalence and related factors of psoriasis and seborrheic dermatitis: a community-based study. Turkish journal of medical sciences, 46(2), 303-309. doi: 10.3906/ sag-1406-51

[3] Borda, L. J., \& Wikramanayake, T. C. (2015). Seborrheic dermatitis and dandruff: a comprehensive review. Journal of clinical and investigative dermatology, 3(2), 10. doi: 10.13188/23731044.1000019

[4] Bunak, V. V. (1941). Антропометрия [Anthropometry]. M.: Наркомпрос РСФСР - M.: People's Commissariat of the RSFSR

[5] Chaplygina, E. V., Aksenova, O. A., Vartanova, O. T., NorArevyan, K. A., \& Evtushenko, A. V. (2014). Современные представления о конституции человека и ее значение для медицины [Modern ideas about the human constitution and its importance for medicine]. Современные проблемы науки и образования - Modern problems of science and education, (5), 468-468.

[6] Dmytrenko, S. V., Obadeh Bassam Abdel-Rahman Al-Qaraleh, Dzevulska I. V., Skoruk, R. V., \& Gunas, I. V. (2020). Features of total, longitudinal and transverse body sizes in men of the general group of patients with mild and severe psoriasis. Вісник Вінницького національного медичного універсиmemy, 24(4), 647-652. doi: 10.31393/reports-vnmedical-202024(4)-15

[7] Gül, A. I., Karaaslan, Ö., \& Çölgeçen, E. (2017). Personality traits and common psychiatric conditions in patients with seborrheic dermatitis. Archives of Clinical Psychiatry (Sao Paulo), 44(1), 6-9. doi: 10.1590/0101-60830000000106

[8] Khasawneh Ahmad Raed, Dmytrenko, S. V., Kizina, I. E., Kyrychenko, Yu. V., \& Prokopenko S. V. (2020). Correlations between the severity of oily skin and the emotional impact of oily skin with anthro-somatotypological parameters of men and women with seborrheic dermatitis. Biomedical and Biosocial Anthropology, (41), 60-66. doi: 10.31393/bba412020-10

[9] Mateshuk-Vatseba, L. R., \& Chaplyk-Chyzho, I. O. (2018). The most pronounced constitutional differences between healthy and sick with pyoderma in men or women in the western middle-thoracic diameter, anterior-posterior middle-sternal diameter distance, as well as smaller values of shoulder width and width of the distal epiphysis of the shoulder).

2. There are only tendencies to higher values in patient's female with severe severity in transverse lower-thoracic diameter and intertrochanteric distance, as well as in patient's male with severe severity in the width of the distal epiphysis of the forearm than in women or men with mild disease course.

3. Among patients with seborrheic dermatitis of varying severity found pronounced manifestations of sexual dimorphism of the width of the distal epiphyses of the long tubular bones of the limbs and transverse diameters of the body (except for pelvis sizes), namely - higher values of these indicators in men.

region of Ukraine. Biomedical and Biosocial Anthropology, (30), 50-55. doi: 10.31393/bba30-2018-03

[10] Nabil Basim Yousif Haddad, Serebrennikova, O. A., Gunas, I. V., Kyrychenko, Yu. V., \& Rekun, T. O. (2021). Total and longitudinal body sizes in men with benign nevi. Reports of Morphology, 27(3), 61-66. doi: 10.31393/morphology-journal2021-27(3)-09

[11] Palamaras, I., Kyriakis, K. P., \& Stavrianeas, N. G. (2012). Seborrheic dermatitis: lifetime detection rates. Journal of the European Academy of Dermatology and Venereology, 26(4), 524-526. doi: 10.1111/j.1468-3083.2011.04079.x

[12] Park, T., Kim, H. J., Myeong, N. R., Lee, H. G., Kwack, I., Lee, J., ... \& An, S. (2017). Collapse of human scalp microbiome network in dandruff and seborrhoeic dermatitis. Experimental dermatology, 26(9), 835-838. doi: 10.1111/exd.13293

[13] Paulino, L. C. (2017). New perspectives on dandruff and seborrheic dermatitis: lessons we learned from bacterial and fungal skin microbiota. European Journal of Dermatology, 27(1), 4-7. doi: 10.1684/ejd.2017.3038

[14] Polesko, I. V. (2007). Особенности распространения антигенов I и II классов системы HLA у больных себорейным дерматитом [Features of the distribution of antigens of classes I and II of the HLA system in patients with seborrheic dermatitis]. Детские инфрекции - Childhood infections, 6(3), 30-34.

[15] Polonskaya, A. S., Shatokhina, E. A., \& Kruglova, L. S. (2020). Себорейный дерматит: современные представления об этиологии, патогенезе и подходах к лечению [Seborrheic dermatitis: modern ideas about the etiology, pathogenesis and approaches to treatment]. Клиническая дерматология и венерология - Clinical Dermatology and Venereology, 19(4), 451-458. doi: 10.17116/ klinderma202019041451

[16] Rather, P. A., Hassan, I., Naaz, S., Rasool, F., \& Reshi, R. (2016). Evaluation of $A B O$ blood types in various dermatoses in Kashmiri population: A case-control study. Journal of Pakistan Association of Dermatology, 24(3), 224-230.

[17] Silventoinen, K., Maia, J., Jelenkovic, A., Pereira, S., Gouveia, E., Antunes, A., ... \& Freitas, D. (2021). Genetics of somatotype and physical fitness in children and adolescents. American Journal of Human Biology, 33(3), e23470. doi: 10.1002/ ajhb.23470

[18] Tanaka, A., Cho, O., Saito, C., Saito, M., Tsuboi, R., \& Sugita, T. (2016). Comprehensive pyrosequencing analysis of the bacterial microbiota of the skin of patients with seborrheic 
dermatitis. Microbiology and immunology, 60(8), 521-526. doi: 10.1111/1348-0421.12398

[19] Wan, D. C., Wong, V. W., Longaker, M. T., Yang, G. P., \& Wei, F. C. (2014). Moisturizing different racial skin types. The Journal of clinical and aesthetic dermatology, 7(6), 25-32. PMID: 25013536

[20] Wikramanayake, T. C., Borda, L. J., Miteva, M., \& Paus, R. (2019). Seborrheic dermatitis-looking beyond Malassezia.
Experimental dermatology, 28(9), 991-1001. doi: 10.1111/ exd.14006

[21] Yamashita, Y., Okano, Y., Ngo, T., Buche, P., Sirvent, A., Girard, F., \& Masaki, H. (2012). Differences in susceptibility to oxidative stress in the skin of Japanese and French subjects and physiological characteristics of their skin. Skin pharmacology and physiology, 25(2), 78-85. doi: 10.1159/000335259 